\title{
Polymorphisms of the pri-miR-34b/c promoter and TP53 codon 72 are associated with risk of colorectal cancer
}

\author{
$\mathrm{JISU} \mathrm{OH}^{1^{*}}$, JONG WOO KIM ${ }^{2 *}$, BO EUN LEE ${ }^{3}$, MOON JU JANG ${ }^{1}$, SO YOUNG CHONG ${ }^{1}$, \\ PIL WON PARK ${ }^{1}$, SEONG GYU HWANG ${ }^{1,3}$, DOYEUN OH ${ }^{1,3}$ and NAM KEUN KIM ${ }^{3}$ \\ Departments of ${ }^{1}$ Internal Medicine and ${ }^{2}$ Surgery, and ${ }^{3}$ Institute for Clinical Research, \\ CHA Bundang Medical Center, CHA University, Seongnam, Republic of Korea
}

Received November 6, 2013; Accepted December 2, 2013

DOI: $10.3892 /$ or.2013.2926

\begin{abstract}
The microRNA (miR)-34 family is a direct transcriptional target of tumor-suppressor TP53 and loss of miR-34 function may impair TP53-mediated cell cycle arrest and apoptosis. In the present study, we investigated whether the single nucleotide polymorphisms (SNPs) rs4938723 (T>C) in the promoter region of $m i R-34 b / c$ and Arg72Pro $(\mathrm{G}>\mathrm{C})$ in codon 72 of TP53 are independently or complementarily associated with the risks and clinical outcomes of colorectal cancer (CRC) and whether the combined effect of these SNPs and metabolic risk factors are related to CRC. We evaluated the SNPs in 545 CRC patients and 428 healthy controls using polymerase chain reaction-restriction fragment length polymorphism (PCR-RFLP) and DNA sequence analysis. We found that the GC and GC/CC genotypes of TP53 Arg72Pro were associated with decreased risk of CRC (adjusted $\mathrm{OR}=0.727$ for $\mathrm{GC}$; OR $=0.735$ for $\mathrm{GC} / \mathrm{CC}$ ). The combined genotypes of TT-GC and CC-GG were significantly associated with reduced $\mathrm{CRC}$ risk (adjusted $\mathrm{OR}=0.628$ for TT-GC; $\mathrm{OR}=0.381$ for CC-GG, respectively). The SNP rs4938723 and diabetes mellitus (DM) together were associated with an increased CRC risk, but the SNP TP53 Arg72Pro CC with DM showed a protective effect against CRC. These findings indicate that rs4938723 in the promoter region of $\mathrm{pri}-\mathrm{miR}-34 \mathrm{~b} / \mathrm{c}$ and the SNP in TP53 codon 72 were related to decreased risk of CRC in the population studied and those metabolic diseases and genetic variants influence each other with regard to CRC susceptibility.
\end{abstract}

Correspondence to: Professor Nam Keun Kim, Institute for Clinical Research, CHA Bundang Medical Center, CHA University, 59 Yatap-ro, Bundang-gu, Seongnam 463-712, Republic of Korea E-mail: nkkim@cha.ac.kr

*Contributed equally

Key words: microRNA-34b/c, TP53 Arg72Pro, polymorphism, risk and prognosis, metabolic diseases, colorectal cancer

\section{Introduction}

Colorectal cancer (CRC) is one of the most common types of cancer (the third and fourth most common cancer in women and men, respectively) in the world and the second leading cause of cancer-related mortality in developed countries. More than 1.2 million cases are diagnosed globally each year, with $\sim 600,000$ deaths $(1,2)$. In order to find new diagnostic and therapeutic tools to reduce CRC-related morbidity, it is key to understand the etiology and biology of CRC. Progression to CRC is caused by an accumulation of various genetic and epigenetic alterations, leading to transformation from a normal tissue to a malignant, and potentially metastatic, tumor. CRC develops through two main genetic pathways that are characterized by different forms of genomic instability, the chromosomal instability (CIN, 85\%) and microsatellite instability (MSI, 15\%) pathways (3-5). Many tumor-suppressor genes and oncogenes have been described, and the discovery of new tumor markers, including those for CRC, continues at a rapid pace.

A new group of biomarkers, microRNAs (miRs), has recently been established. miRs are 20-25-nucleotide noncoding RNAs that negatively regulate gene transcription at the transcriptional or post-transcriptional level by interacting with the 3' untranslated regions (UTRs) of specific messenger RNAs (mRNAs) and are key modulators in the control of biological processes, such as cell development, differentiation, proliferation and apoptosis (6-9). Estimates based on bioinformatics and microarray analyses suggest that $>30 \%$ of all genes are regulated by multiple miRs (10). miR-34s form an evolutionarily conserved miR family, with $m i R-34 a, m i R-34 b$ and $m i R-34 c$ occurring in vertebrates. The $m i R-34 a$ and $m i R-34 b / c$ loci are regulated directly by interaction with TP53, which induces apoptosis, cell cycle arrest and senescence (11-13). In addition, reduced $m i R-34 a$ expression is a frequent feature of both pancreatic tumors and neuroblastomas $(14,15)$ and reduced $m i R-34 b / c$ expression has been observed in non-small cell lung cancer (16). CpG methylation of $m i R-34 b / c$ has been found in CRC $(2,17)$, oral squamous cell carcinoma (18), and malignant melanoma, where it correlated with metastatic potential (19).

The downregulation of miR-34 family members in cancer suggests that these miRs function as tumor-suppressor genes, suggesting a possible role as prognostic markers (20). Several mechanisms regulating miR expression, including gene ampli- 
fication, deletion, epigenetic alterations and single-nucleotide substitution, have been implicated, but not demonstrated $(20,21)$. Although single nucleotide polymorphisms (SNPs) in miRs are not considered functionally important, nucleotide variations in primary (pri)- or precursor (pre)-miRs may affect miR processing and modify miR expression (22). Recently, studies reported that a potentially functional SNP, rs4938723, in the promoter region of $\mathrm{pri}-\mathrm{miR}-34 \mathrm{~b} / \mathrm{c}$ may contribute to susceptibility to hepatocellular carcinoma (23), CRC (24), endometrial cancer (25) and survival in breast cancer (26). However, there are few reports on the relationship between SNPs in the $m i R-34 b / c$ promoter and risk and prognostic significance in CRC patients.

In the present study, we investigated whether the SNPs rs4938723 $(\mathrm{T}>\mathrm{C})$ in the promoter region of $m i R-34 b / c$ and Arg72Pro $(\mathrm{G}>\mathrm{C})$ in codon 72 of TP53 are independently or complementarily associated with the risk and clinical outcomes of CRC and whether the combined effect of these SNPs and metabolic risks (diabetes and hypertension) is related to progression of CRC, which is known to be associated with metabolic disease $(27,28)$ in the Korean population.

\section{Materials and methods}

Patients and clinical samples. From June 2000 to January 2009, blood samples were collected from 545 patients diagnosed with $\mathrm{CRC}$ at CHA Bundang Medical Center of CHA University in South Korea. We retrospectively obtained information concerning the age; gender; underlying conditions [hypertension (HTN), diabetes mellitus (DM), body mass index (BMI), smoking and alcohol consumption]; tumor size, stage and site; time to progression; and time to mortality. We estimated homocysteine and folic acid levels. The American Joint Committee on Cancer: Classification and Stage Groupings, 7th edition was used for tumor assessment. The cancer-free control group consisted of 428 individuals who were randomly selected from participants in a health-screening program to exclude those with a history of cancer and other medical diseases. All study subjects provided written consent and all were ethnic Koreans. The subjects' recruitment was approved by the Institutional Review Board of CHA Bundang Medical Center.

Genotyping. DNA was extracted from leukocytes using a G-DEX ${ }^{\mathrm{TM}}$ II Genomic DNA Extraction kit (iNtRON Biotechnology, Seongnam, Korea), according to the manufacturer's instructions. The SNPs $m i R-34 b / c$ rs4938723 and TP53 Arg72Pro rs1042522 were genotyped by polymerase chain reaction-restriction fragment length polymorphism (PCR-RFLP) assays. Primer sequences used for amplification of rs4938723 were: (forward) 5'-CCT CTG GGA ACC TTC TTT GAC CAA T-3' and (reverse) 5'-TGA GAT CAA GGC CAT ACC ATT CAA GA-3'. Primer sequences used for amplification of TP53 Arg72Pro were: (forward) 5'-TTG CCG TCC CAA GCA ATG GAT GA-3' and (reverse) 5'-TCT GGG AAG GGA CAG AAG ATG AC-3'. For each of the polymorphisms, $30 \%$ of the PCR assays were randomly chosen and repeated, followed by DNA sequencing to validate the RFLP findings. Sequencing was performed using an ABI 3730xl DNA Analyzer (Applied Biosystems, Foster City, CA, USA). The concordance of the quality control samples was $100 \%$.
Statistical analysis. The genotypes for each SNP were analyzed as a three-group categorical variable (reference model) and were also grouped according to the dominant and recessive model. Odds ratios (ORs), adjusted odds ratios (AORs) and $95 \%$ confidence intervals (CIs) were used to calculate the strength of association. To analyze baseline characteristics, we used a Chi-square test for categorical data when comparing patient and control baseline data. Multivariate analysis was performed to select independent risk factors for CRC among genotypes and clinical variables using logistic regression analysis. The overall survival was compared using the Kaplan-Meier method and potential variables were verified by multivariate analysis using a Cox regression model. All tests were two-tailed, and a P-value $<0.05$ was deemed to indicate a statistically significant difference. Analyses were performed using GraphPad Prism 4.0 (GraphPad Software, San Diego, CA, USA) and MedCalc version 11.1.1.0 (MedCalc Software, Ostend, Belgium). The distribution of allele frequencies for the rs4938723 (T>C) and TP53 Arg72Pro (G>C) gene polymorphisms were calculated by Chi-square test to determine whether the observed genotype distributions conformed to the expected Hardy-Weinberg equilibrium (29).

\section{Results}

Population. Baseline characteristics of patients with CRC and controls are shown in Table I. The mean age was 62 years in CRC patients and 61 years in controls. Of the CRC patients, $302(55.4 \%)$ were male. Approximately $61.5 \%$ of CRC cases had HTN and $33.6 \%$ had DM; these were significantly higher values than observed among controls (34.1 and 6.1\%, respectively) $(\mathrm{P}<0.001)$. However, the number of smokers in the control group exceeded that for CRC patients. Tumors occurred most frequently in the rectum and proximal colon. With regard to tumor-node-metastasis (TNM) staging, the majority of patients $(80.7 \%)$ had stage II-III disease.

Variant genotypes of TP53 codon 72 are related to reduced $C R C$ risk. Genotype frequencies of $m i R-34 b / c$ rs 4938723 and TP53 Arg72Pro rs1042522 in CRC patients and controls are shown in Table II. In multivariate analysis, the variant genotypes of TP53 Arg72Pro GC and GC/CC were associated with a significantly decreased risk of CRC compared with the wild-type $\mathrm{GG}$ genotype $(\mathrm{AOR}=0.727,95 \% \mathrm{CI}=0.550-0.960$ for $\mathrm{GC}$; $\mathrm{AOR}=0.735,95 \% \mathrm{CI}=0.565-0.958$ for $\mathrm{GC} / \mathrm{CC}$ ). However, no overall association was observed between $m i R-34 b / c$ rs4938723 and CRC risk in our study population. The observed genotype frequencies for $m i R-34 b / c$ rs4938723 ( $>$ C ) and TP53 Arg72Pro (G>C) polymorphisms in the cases and controls were all as expected for Hardy-Weinberg equilibrium $(\mathrm{P}>0.05)$.

Combined genotype effects of rs 4938723 and TP53 (TT/GC and $C C / G G)$ are associated with decreased $C R C$ risk in colon cancer patients. Combined genotype analyses were conducted to evaluate the combined effects of the two polymorphisms on the risk of CRC (Table III). Nine combined genotypes were estimated from the two polymorphisms in CRC patients. In the multivariate analysis, combined genotypes TT/GC and CC/GG were associated with significantly decreased CRC risk when 
Table I. Baseline characteristics of CRC patients and controls.

\begin{tabular}{lccc}
\hline Variable $n(\%)$ & Controls $(\mathrm{n}=428)$ & CRC patients $(\mathrm{n}=545)$ & OR $(95 \%$ CI $)$ \\
\hline Age (years, mean \pm SD) & $60.75 \pm 11.73$ & $62.07 \pm 12.15$ & $1.008(0.998-1.019)$ \\
Gender (male) & $172(40.2)$ & $302(55.4)$ & $1.379(1.100-1.729)$ \\
Hypertension & $146(34.1)$ & $335(61.5)$ & $1.802(1.429-2.272)$ \\
Diabetes mellitus & $26(6.1)$ & $183(33.6)$ & $10.120(6.657-15.380)$ \\
Body mass index $\geq 25.0 \mathrm{~kg} / \mathrm{m}^{2}$ & $96(22.4)$ & $143(26.2)$ & $1.170(0.877-1.560)$ \\
Smoking & $140(32.7)$ & $125(22.9)$ & $0.701(0.534-0.921)$ \\
Tumor size $\geq 5 \mathrm{~cm}$ & NA & $319(58.5)$ & 0.005 \\
Tumor site & & & 0.010 \\
Proximal colon & NA & $180(33.0)$ & \\
Distal colon & NA & $123(22.6))$ & \\
Mixed colon & NA & $7(1.3)$ & \\
Rectum & NA & $225(41.3)$ & \\
TNM stage & & $55(10.1)$ & \\
I & NA & $228(41.8)$ & \\
II & NA & $212(38.9)$ & \\
III & NA & $49(9.0)$ & \\
IV & NA & & \\
\hline
\end{tabular}

${ }^{a}$ Chi-square test for categorical data, two-sided t-test for continuous data. CRC, colorectal cancer; OR, odds ratio; CI, confidence interval; $\mathrm{SD}$, standard deviation; TNM, tumor-node-metastasis; NA, not applicable.

compared with the wild-type TT/GG genotype $(\mathrm{AOR}=0.628$, 95\% CI $=0.422-0.934$ for $\mathrm{TT} / \mathrm{GC} ; \mathrm{AOR}=0.381,95 \%$ $\mathrm{CI}=0.183-0.793$ for $\mathrm{CC} / \mathrm{GG}$, respectively). This association was observed only in patients with colon, not rectal, cancer and, moreover, was observed only in proximal colon cancer patients (data not shown).

SNP rs4938723 with DM is associated with increased CRC risk. Table IV shows CRC risk by combined genetic-environmental effects (HTN, DM, homocysteine and folic acid). TP53 Arg72Pro GG and all genotypes of rs4938723 with HTN were significantly associated with increased risk of CRC. All DM patients, in particular, showed strong positive association with CRC, regardless of genotype. The polymorphism rs4938723 with DM was associated with a significantly increased CRC risk compared with wild-type TT and TP53 Arg72Pro CC with DM significantly decreased the risk when compared with wild-type GG. No differences were observed between homocysteine and folic acid levels for any genotype (data not shown). A homocysteine level $>11.7 \mu \mathrm{mol} / 1$ was associated with increased risk of CRC in rs4938723 TC and TC/CC, but with decreased risk for TP53 Arg72Pro SNPs. Folic acid level $<4.45 \mathrm{ng} / \mathrm{ml}$ was associated with an increased CRC risk, but the rs4938723 and TP53 Arg72Pro polymorphisms decreased the risk of CRC when compared with wild-type (Table IV).

Polymorphisms rs4938723 and TP53 Arg72Pro show a trend toward, but are not significantly associated with, improved survival. The 3-year survival rate was estimated in each $m i R-34 b / c$ rs4938723 and TP53 Arg72Pro patient group (Table V). In the multivariate analysis, overall survival of the variant $m i R-34 b / c$ rs4938723 and TP53 Arg72Pro genotypes was more evident in subjects carrying polymorphisms than in wild-type. However, we did not find a significant asso-
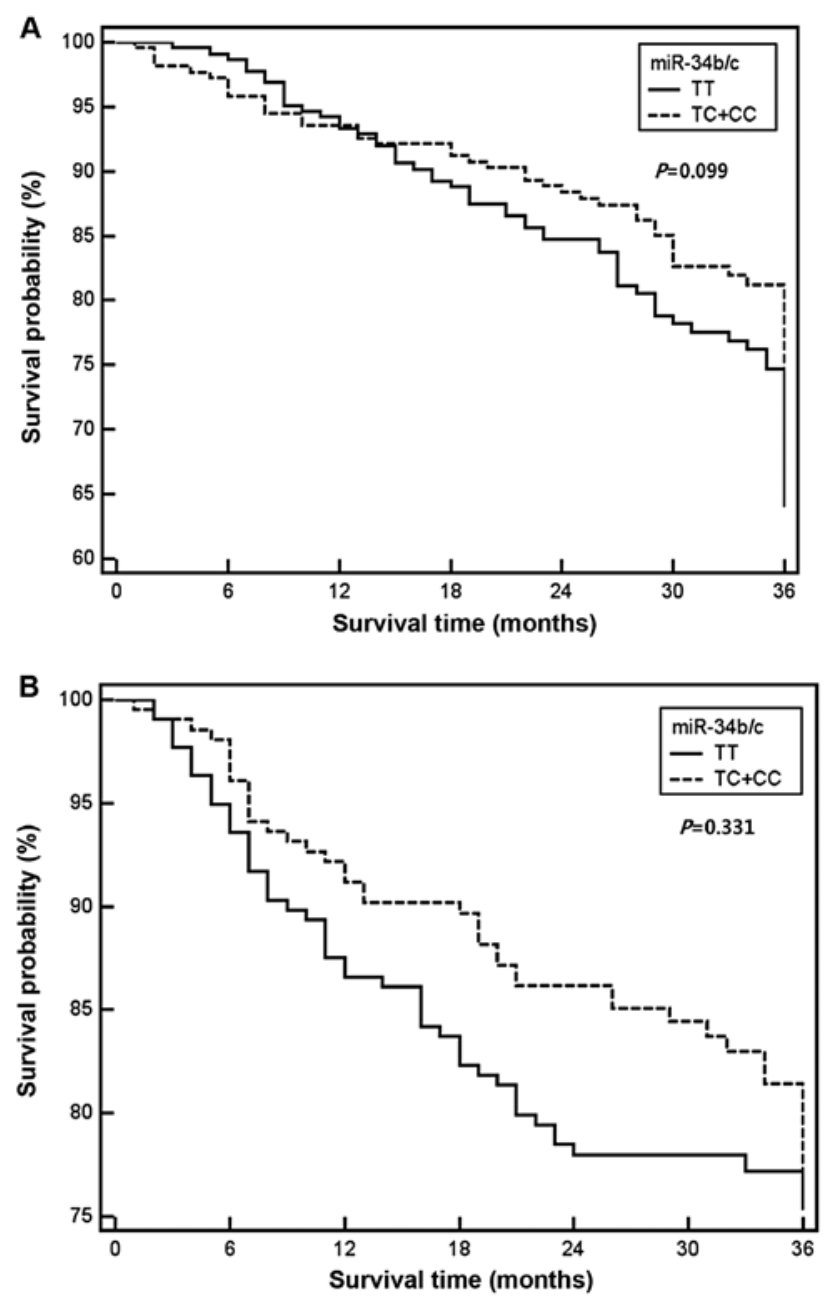

Figure 1. (A) Overall survival, (B) relapse free survival according to $m i R-34 \mathrm{~b} / \mathrm{c}$ rs4938723 polymorphisms in CRC patients. CRC, colorectal cancer. 


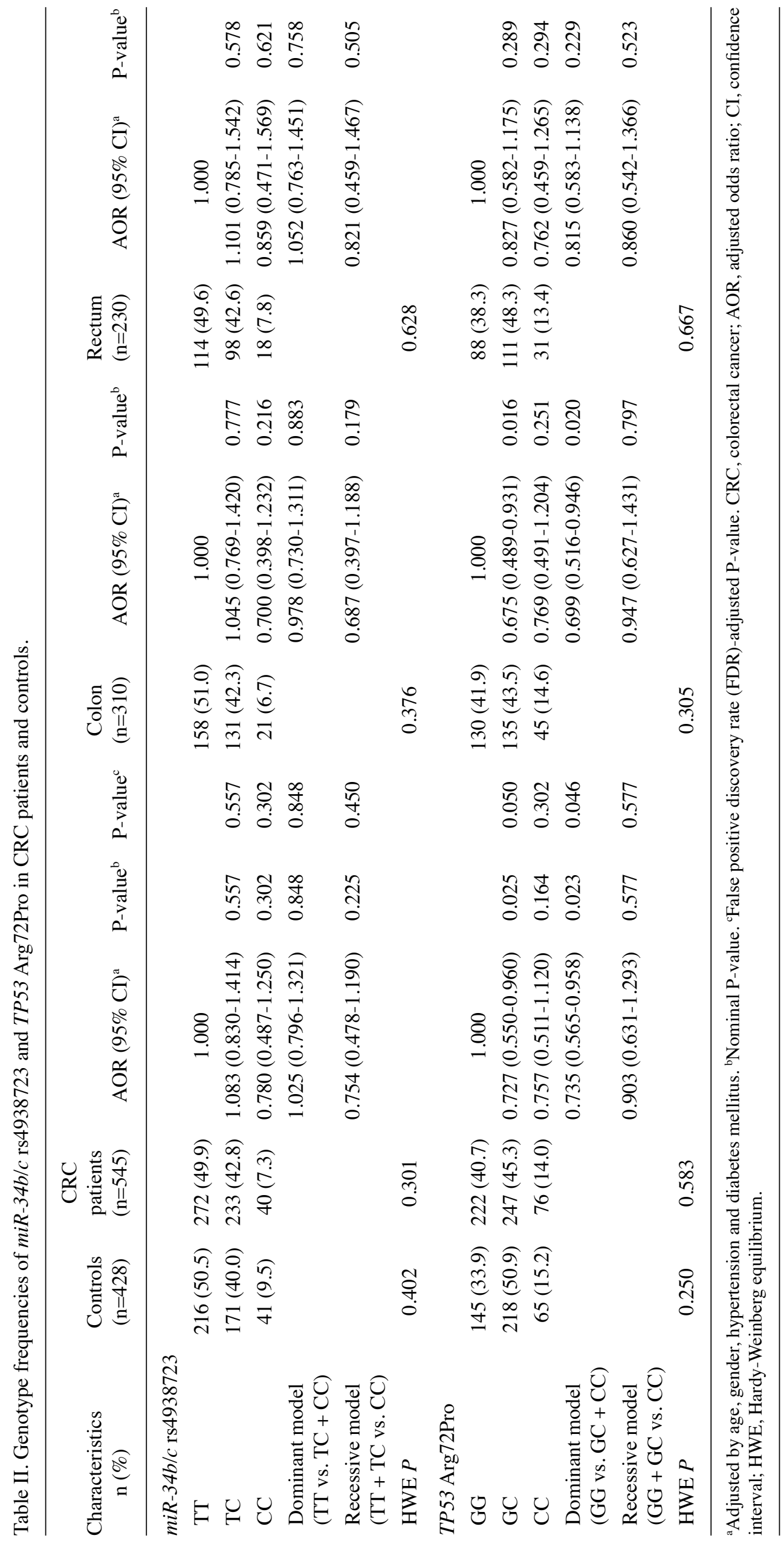


ciation between $m i R-34 b / c$ rs4938723 and TP53 Arg72Pro genotypes and survival of CRC (Fig. 1). Stratified analyses (Table VI) showed that the risk reduction effect of the variant TP53 Arg72Pro GC/CC genotypes was significant in subjects without HTN (AOR $=0.635,95 \% \mathrm{CI}=0.418-0.966$ ). However, no significant interactions were observed between $m i R-34 b / c$ rs4938723 TC/CC and other clinical features.

\section{Discussion}

In the present study on CRC in a Korean population, we investigated the correlation between the SNPs rs4938723, in the promoter region of pri-miR-34b/c and TP53 Arg72Pro and the risk of CRC. We found that the TP53 Arg72Pro polymorphism was significantly associated with a decreased risk of CRC. The combined genotypes rs4938723 CC and TP53 GG had a tendency to protect individuals against CRC. This finding suggests that SNPs in the promoter regions of miRs may have important roles in the etiology of CRC, providing novel biomarkers for malignancies. This tendency was shown for cancer of the colon, particularly the proximal colon, but not for rectal cancer. Further investigation of the relationship between the site of cancer and genotype is required. Recently, studies reported that TP53 influences the expression of $m i R-34 b / c$ in a one-way relationship. However, rs4938723 TT and TP53 Arg72Pro GC were also associated with decreased CRC risk in the present study, which suggests that TP53 and miR-34b/c may interact bidirectional and supports the concept that CRC is a complex disease involving multiple genes.

We also found that HTN or DM was associated with a significantly increased risk of CRC, regardless of genotype (Table IV). SNP rs4938723 with DM was associated with increased CRC risk when compared with wild-type, but TP53 Arg72Pro CC with DM was associated with decreased risk when compared with wild-type. Moreover, decreased levels of homocysteine and folic acid showed a positive correlation with the risk of CRC (Table VII). At folic acid levels of $<4.45 \mathrm{ng} / \mathrm{ml}$, both the rs4938723 and TP53 codon 72 SNPs were related to a decreased risk of CRC. At homocysteine levels $>11.70 \mu \mathrm{mol} / 1$, rs4938723 was positively correlated with CRC risk, but the TP53 codon 72 SNP was inversely correlated. These findings suggest that genetic factors and environmental factors, such as metabolic diseases, influence each other in CRC and may implicate miRs as pathophysiologic linkers/modulators between metabolic syndrome and cancer.

Rs4938723 is located within the $\mathrm{CpG}$ island of pri$m i R-34 b / c$ (423-bp upstream of the transcription start site), making it a potential binding site for GATA-X transcription factors. According to the web-based SNP analysis tool TFSEARCH 1.3, GATA family members bind to promoters of many genes and directly activate or suppress expression of target genes and may be involved in carcinogenesis (30). Therefore, SNP rs4938723 (T>C) may affect the expression level of $m i R-34 b / c$. Ectopic $m i R-34 b / c$ caused cell cycle arrest in the G1 phase (31) and $m i R-34 b / c$ inhibited proliferation and colony formation in soft agar (11). The relationship between miR expression in tumors and prognosis, with regard to both the treatment response rate and survival, is of increasing interest. This polymorphism has been reported to be associated with susceptibility to hepatocellular carcinoma (23), CRC (24), 
Table IV. Colorectal cancer risk by combined gene-environmental effects.

\begin{tabular}{|c|c|c|c|c|}
\hline Genotypes & $\begin{array}{l}\text { Without HTN } \\
\text { AOR }(95 \% \mathrm{CI})^{\mathrm{a}}\end{array}$ & $\begin{array}{c}\text { With HTN } \\
\operatorname{AOR}(95 \% \mathrm{CI})^{\mathrm{a}}\end{array}$ & $\begin{array}{c}\text { Without DM } \\
\text { AOR }(95 \% \mathrm{CI})^{\mathrm{a}}\end{array}$ & $\begin{array}{c}\text { With DM } \\
\operatorname{AOR}(95 \% \mathrm{CI})^{\mathrm{a}}\end{array}$ \\
\hline$m i R-34 b / c$ rs4938723 TT & 1.000 & $2.985(1.962-4.542)^{b}$ & 1.000 & $5.737(3.152-10.442)^{\mathrm{b}}$ \\
\hline$m i R-34 b / c$ rs $4938723 \mathrm{TC}$ & $1.021(0.678-1.538)$ & $3.570(2.252-5.661)^{b}$ & $1.045(0.760-1.436)$ & $6.545(3.520-12.171)^{\mathrm{b}}$ \\
\hline$m i R-34 b / c$ rs $4938723 \mathrm{CC}$ & $0.574(0.264-1.249)$ & $3.098(1.427-6.725)^{\mathrm{b}}$ & $0.752(0.429-1.319)$ & $5.246(1.130-24.359)^{\mathrm{b}}$ \\
\hline$m i R-34 b / c$ rs $4938723 \mathrm{TC}+\mathrm{CC}$ & $0.980(0.679-1.415)$ & $3.964(2.643-5.945)^{\mathrm{b}}$ & $1.009(0.758-1.343)$ & $8.323(4.498-15.402)^{\mathrm{b}}$ \\
\hline TP53 Arg72Pro GG & 1.000 & $2.007(1.215-3.315)^{\mathrm{b}}$ & 1.000 & $7.183(3.428-15.052)^{\mathrm{b}}$ \\
\hline TP53 Arg72Pro GC & $0.562(0.359-0.880)^{\mathrm{b}}$ & $2.362(1.426-3.913)$ & $0.798(0.573-1.111)$ & $5.699(3.019-10.760)^{\mathrm{b}}$ \\
\hline TP53 Arg72Pro CC & $0.846(0.475-1.510)$ & $1.734(0.855-3.515)$ & $0.938(0.589-1.494)$ & $2.605(1.116-6.082)^{\mathrm{b}}$ \\
\hline \multirow[t]{2}{*}{ TP53 Arg72Pro GC + CC } & $0.704(0.476-1.041)$ & $2.595(1.656-4.066)^{\mathrm{b}}$ & $0.780(0.579-1.051)$ & $5.398(3.091-9.429)^{\mathrm{b}}$ \\
\hline & $\begin{array}{c}\mathrm{Hcy} \leq 11.70 \mu \mathrm{mol} / 1 \\
\text { AOR }(95 \% \mathrm{CI})^{\mathrm{a}}\end{array}$ & $\begin{array}{c}11.70<\mathrm{Hcy} \mu \mathrm{mol} / \mathrm{l} \\
\operatorname{AOR}(95 \% \mathrm{CI})^{\mathrm{a}}\end{array}$ & $\begin{array}{l}4.45<\mathrm{FA} \mathrm{ng} / \mathrm{ml} \\
\operatorname{AOR}(95 \% \mathrm{CI})^{\mathrm{a}}\end{array}$ & $\begin{array}{l}\mathrm{FA} \leq 4.45 \mathrm{ng} / \mathrm{ml} \\
\operatorname{AOR}(95 \% \mathrm{CI})^{\mathrm{a}}\end{array}$ \\
\hline$m i R-34 b / c$ rs4938723 TT & 1.000 & $1.375(0.885-2.134)$ & 1.000 & $3.406(2.127-5.453)^{\mathrm{b}}$ \\
\hline$m i R-34 b / c$ rs $4938723 \mathrm{TC}$ & $1.008(0.731-1.389)$ & $1.996(1.236-3.223)^{\mathrm{b}}$ & $1.238(0.898-1.709)$ & $2.490(1.528-4.056)^{\mathrm{b}}$ \\
\hline$m i R-34 b / c$ rs $4938723 \mathrm{CC}$ & $0.637(0.362-1.121)$ & $2.447(0.750-7.979)$ & $0.715(0.396-1.294)$ & $2.430(0.890-6.637)$ \\
\hline$m i R-34 b / c$ rs $4938723 \mathrm{TC}+\mathrm{CC}$ & $0.929(0.685-1.261)$ & $2.055(1.302-3.243)^{\mathrm{b}}$ & $1.136(0.836-1.545)$ & $2.483(1.577-3.912)^{\mathrm{b}}$ \\
\hline TP53 Arg72Pro GG & 1.000 & $2.904(1.641-5.138)^{b}$ & 1.000 & $3.438(1.922-6.148)^{\mathrm{b}}$ \\
\hline TP53 Arg72Pro GC & $0.814(0.581-1.140)$ & $1.076(0.682-1.699)$ & $0.726(0.518-1.019)$ & $1.809(1.139-2.876)^{\mathrm{b}}$ \\
\hline TP53 Arg72Pro CC & $0.926(0.588-1.460)$ & $1.389(0.596-3.234)$ & $0.847(0.534-1.346)$ & $2.218(0.972-5.064)$ \\
\hline TP53 Arg72Pro GC + CC & $0.842(0.614-1.155)$ & $1.143(0.745-1.753)$ & $0.755(0.549-1.037)$ & $1.895(1.234-2.909)^{\mathrm{b}}$ \\
\hline
\end{tabular}

${ }^{a}$ Adjusted by age, gender, hypertension and diabetes mellitus. ${ }^{\mathrm{b}} \mathrm{P}<0.05$. HTN, hypertension; DM, diabetes mellitus; AOR, adjusted odds ratio; CI, confidence interval; Hcy, homocysteine; FA, folic acid.

Table V. Multivariate survival analysis according to $m i R-34 b / c$ rs4938723 and TP53 Arg72Pro polymorphisms.

\begin{tabular}{|c|c|c|c|c|c|c|c|}
\hline \multirow[b]{2}{*}{$\begin{array}{c}\text { Characteristics } \\
\mathrm{n}(\%)\end{array}$} & \multirow[b]{2}{*}{$\begin{array}{c}\mathrm{CRC} \\
\text { patients } \\
(\mathrm{n}=545)\end{array}$} & \multicolumn{3}{|c|}{ Overall survival } & \multicolumn{3}{|c|}{ Relapse-free survival } \\
\hline & & $\begin{array}{l}\text { Mortality } \\
(\mathrm{n}=112)\end{array}$ & $\begin{array}{l}\text { Adjusted HR } \\
(95 \% \mathrm{CI})\end{array}$ & P-value & $\begin{array}{l}\text { Relapse } \\
(\mathrm{n}=75)\end{array}$ & $\begin{array}{l}\text { Adjusted HR } \\
(95 \% \mathrm{CI})\end{array}$ & P-value \\
\hline \multicolumn{8}{|l|}{$m i R-34 b / c$ rs 4938723} \\
\hline TT & $272(49.9)$ & $64(57.1)$ & 1.000 & & $42(56.0)$ & 1.000 & \\
\hline $\mathrm{TC}$ & $233(42.8)$ & $43(38.4)$ & $0.716(0.476-1.077)$ & 0.111 & $30(40.0)$ & $0.711(0.456-1.108)$ & 0.134 \\
\hline $\mathrm{CC}$ & $40(7.3)$ & $5(4.5)$ & $0.582(0.233-1.451)$ & 0.248 & $3(4.0)$ & $0.804(0.315-2.050)$ & 0.649 \\
\hline $\begin{array}{l}\text { Dominant model } \\
\text { (TT vs. TC + CC) }\end{array}$ & & & $0.704(0.475-1.043)$ & 0.082 & & $0.729(0.477-1.116)$ & 0.148 \\
\hline $\begin{array}{l}\text { Recessive model } \\
(\mathrm{TT}+\mathrm{TC} \text { vs. CC) }\end{array}$ & & & $0.863(0.338-2.208)$ & 0.760 & & $0.899(0.365-2.217)$ & 0.818 \\
\hline \multicolumn{8}{|l|}{ TP53 Arg72Pro } \\
\hline GG & $222(40.7)$ & $50(44.6)$ & 1.000 & & $34(45.3)$ & 1.000 & \\
\hline $\mathrm{GC}$ & $247(45.3)$ & $53(47.3)$ & $0.862(0.577-1.286)$ & 0.469 & $35(46.7)$ & $0.813(0.524-1.260)$ & 0.356 \\
\hline $\mathrm{CC}$ & $76(14.0)$ & $9(8.1)$ & $0.565(0.274-1.165)$ & 0.124 & $6(8.0)$ & $0.653(0.310-1.374)$ & 0.264 \\
\hline $\begin{array}{l}\text { Dominant model } \\
(\mathrm{GG} \text { vs. } \mathrm{GC}+\mathrm{CC})\end{array}$ & & & $0.809(0.550-1.190)$ & 0.285 & & $0.782(0.515-1.189)$ & 0.253 \\
\hline $\begin{array}{l}\text { Recessive model } \\
(\mathrm{GG}+\mathrm{GC} \text { vs. CC })\end{array}$ & & & $0.630(0.318-1.249)$ & 0.188 & & $0.752(0.375-1.510)$ & 0.426 \\
\hline
\end{tabular}

Adjusted by age, gender, tumor site, tumor size, differentiation, lymph-node-metastasis and tumor-node-metastasis stage. CRC, colorectal cancer; HR, hazard ratio; CI, confidence interval. 
Table VI. Stratified effect of $m i R-34 b / c$ rs4938723 and TP53 polymorphisms on colorectal cancer risk.

\begin{tabular}{|c|c|c|c|c|c|c|}
\hline \multirow[b]{2}{*}{ Variables } & \multicolumn{3}{|c|}{$m i R-34 b / c$ rs4938723 TC + CC } & \multicolumn{3}{|c|}{ TP53 Arg72Pro GC + CC } \\
\hline & $\operatorname{AOR}(95 \% \mathrm{CI})^{\mathrm{a}}$ & P-value ${ }^{b}$ & $\mathrm{P}$-value $\mathrm{e}^{\mathrm{c}}$ & $\operatorname{AOR}(95 \% \mathrm{CI})^{\mathrm{a}}$ & $\mathrm{P}$-value $\mathrm{b}^{\mathrm{b}}$ & $P$-value \\
\hline \multicolumn{7}{|c|}{ Age (years) } \\
\hline$<62$ & $0.986(0.661-1.470)$ & 0.943 & 0.965 & $0.819(0.546-1.228)$ & 0.334 & 0.904 \\
\hline$\geq 62$ & $1.009(0.675-1.508)$ & 0.965 & 0.965 & $0.847(0.550-1.306)$ & 0.452 & 0.904 \\
\hline \multicolumn{7}{|l|}{ Gender } \\
\hline Male & $1.182(0.794-1.760)$ & 0.410 & 0.605 & $0.965(0.635-1.465)$ & 0.866 & 0.866 \\
\hline Female & $0.856(0.570-1.285)$ & 0.454 & 0.605 & $0.695(0.457-1.058)$ & 0.090 & 0.360 \\
\hline \multicolumn{7}{|c|}{ Hypertension } \\
\hline Yes & $1.087(0.722-1.637)$ & 0.689 & 0.747 & $1.086(0.716-1.645)$ & 0.698 & 0.747 \\
\hline No & $0.938(0.633-1.388)$ & 0.747 & 0.747 & $0.635(0.418-0.966)$ & 0.034 & 0.136 \\
\hline \multicolumn{7}{|c|}{ Diabetes mellitus } \\
\hline Yes & $1.150(0.524-2.524)$ & 0.728 & 0.943 & $0.715(0.300-1.704)$ & 0.449 & 0.898 \\
\hline No & $0.989(0.731-1.338)$ & 0.943 & 0.943 & $0.839(0.613-1.149)$ & 0.274 & 0.898 \\
\hline \multicolumn{7}{|c|}{ Tumor site } \\
\hline Colon & $0.989(0.714-1.369)$ & 0.946 & 0.999 & $0.756(0.540-1.060)$ & 0.105 & 0.420 \\
\hline Rectum & $1.057(0.737-1.515)$ & 0.765 & 0.999 & $1.000(0.684-1.462)$ & 0.999 & 0.999 \\
\hline \multicolumn{7}{|c|}{ TNM stage } \\
\hline $\mathrm{I}+\mathrm{II}$ & $1.117(0.798-1.565)$ & 0.519 & 0.643 & $0.849(0.598-1.205)$ & 0.359 & 0.643 \\
\hline III+IV & $0.922(0.655-1.298)$ & 0.643 & 0.643 & $0.824(0.577-1.176)$ & 0.286 & 0.643 \\
\hline
\end{tabular}

${ }^{a}$ Adjusted by age, gender, hypertension and diabetes mellitus. ${ }^{b}$ Nominal P-value. ${ }^{c}$ False positive discovery rate (FDR)-adjusted P-value. AOR, adjusted odds ratio; CI, confidence interval; TNM, tumor-node-metastasis.

Table VII. Homocysteine and folic acid levels in CRC patients and controls.

\begin{tabular}{|c|c|c|c|c|}
\hline Homocysteine level & Controls $(n=423)$ & CRC patients $(n=463)$ & OR $(95 \% \mathrm{CI})$ & P-value \\
\hline Hcy $\leq 7.26$ & $104(24.6)$ & $118(25.5)$ & 1.000 & \\
\hline $7.26<$ Hcy $\leq 8.29$ & $130(30.7)$ & $93(20.1)$ & $0.631(0.433-0.917)$ & 0.016 \\
\hline $8.29<$ Hcy $\leq 11.70$ & $107(25.3)$ & $113(24.4)$ & $0.931(0.641-1.352)$ & 0.707 \\
\hline $11.70<$ Hcy & $82(19.4)$ & $139(30.0)$ & $1.494(1.022-2.184)$ & 0.038 \\
\hline Folate level & Controls $(n=421)$ & CRC patients $(n=462)$ & OR $(95 \% \mathrm{CI})$ & P-value \\
\hline $\mathrm{FA} \leq 4.45$ & $66(15.7)$ & $156(33.8)$ & 1.000 & \\
\hline $4.45<\mathrm{FA} \leq 6.39$ & $121(28.7)$ & $99(21.4)$ & $0.346(0.234-0.512)$ & $<0.0001$ \\
\hline $6.39<\mathrm{FA} \leq 9.36$ & $117(27.8)$ & $104(22.5)$ & $0.376(0.254-0.556)$ & $<0.0001$ \\
\hline $9.36<\mathrm{FA}$ & $117(27.8)$ & $103(22.3)$ & $0.373(0.252-0.551)$ & $<0.0001$ \\
\hline
\end{tabular}

CRC, colorectal cancer; OR, odds ratio; CI, confidence interval; Hcy, homocysteine; FA, folic acid.

survival of breast cancer (26), renal cell carcinoma (32), nonsmall cell lung (33) and oral cancer (18).

Arg72Pro is the most widely investigated of the variations in the TP53 gene. The 72Arg allele induces apoptosis more efficiently than the 72Pro allele (34). It has been reported that homozygosity for Pro of TP53 Arg72Pro is potentially a risk factor for cancer of the lung, esophagus, stomach, breast, nasopharynx, urothelium and prostate (35-37). In CRC, meta-analysis was performed to estimate the effect of the
TP53 Arg72Pro polymorphism and CRC risk, and no significant association was identified (38). In contrast to that result, we found a negative relationship between the TP53 Arg72Pro polymorphism and CRC risk in the Korean population.

Our study has several limitations. First, the enrolled patients were selected at a single institution in Korea and the sample size may limit the statistical power, especially for evaluating the connection between SNPs and CRC risk and survival in detailed genotype subgroups. Second, as the study 
was hospital-based, the cases and controls could not be representative of the general population. This possible selection bias could not be avoided. Finally, the mechanisms underlying the effects of genetic polymorphisms on the levels of pre/ mature miRs and the identity of the miR target genes remain unknown and should be determined in future studies.

In conclusion, although we identified no significant prognostic value of SNPs for CRC, we found that SNPs rs4938723 and TP53 Arg72Pro show a trend toward improved survival and that the TP53 Arg72Pro CC genotype and dominant model $(\mathrm{GC}+\mathrm{CC})$ significantly decrease the risk of CRC. Additionally, the combined genotype rs4938723 and TP53 Arg72Pro (TT/GC and CC/GG) was significantly associated with decreased CRC risk in the Korean population. Also, SNP rs4938723 with DM was more closely related to increased CRC risk than the wild-type genotype. Future studies in multiethnic populations are warranted to validate our results and to define the functional effects of these SNPs on CRC.

\section{Acknowledgements}

This study was partially supported by a National Research Foundation (NRF) of Korea Grant funded by the Korean Government (2009-0075784 and 2012R1A1A2007033), and a Priority Research Centers Program Grant, administered by the NRF and funded by the Ministry of Education (2009-0093821), Republic of Korea.

\section{References}

1. Siegel R, Naishadham D and Jemal A: Cancer statistics, 2012. CA Cancer J Cin 62: 10-29, 2012.

2. Hrašovec $S$ and Glavač D: MicroRNAs as novel biomarkers in colorectal cancer. Front Genet 3: 180, 2012.

3. Cunningham JM, Christensen ER, Tester DJ, et al: Hypermethylation of the $h M L H 1$ promoter in colon cancer with microsatellite instability. Cancer Res 58: 3455-3460, 1998.

4. Toyota M, Ahuja N, Ohe-Toyota M, Herman JG, Baylin SB and Issa JP: CpG island methylator phenotype in colorectal cancer. Proc Natl Acad Sci USA 96: 8681-8686, 1999.

5. Shen L, Toyota M, Kondo Y, et al: Integrated genetic and epigenetic analysis identifies three different subclasses of colon cancer. Proc Natl Acad Sci USA 104: 18654-18659, 2007.

6. Iorio MV and Croce CM: MicroRNA dysregulation in cancer: diagnostics, monitoring and therapeutics. A comprehensive review. EMBO Mol Med 4: 143-159, 2012.

7. Fazi F and Nervi C: MicroRNA: basic mechanisms and transcriptional regulatory networks for cell fate determination. Cardiovasc Res 79: 553-561, 2008.

8. Meister $\mathrm{G}$ and Tuschl T: Mechanisms of gene silencing by double-stranded RNA. Nature 431: 343-349, 2004

9. Pillai RS, Bhattacharyya SN and Filipowicz W: Repression of protein synthesis by miRNAs: how many mechanisms? Trends Cell Biol 17: 118-126, 2007.

10. Lim LP, Lau NC, Garrett-Engele P, et al: Microarray analysis shows that some microRNAs downregulate large numbers of target mRNAs. Nature 433: 769-773, 2005.

11. Corney DC, Flesken-Nikitin A, Godwin AK, Wang W and Nikitin AY: MicroRNA-34b and MicroRNA-34c are targets of p53 and cooperate in control of cell proliferation and adhesionindependent growth. Cancer Res 67: 8433-8438, 2007.

12. He L, He X, Lim LP, et al: A microRNA component of the p53 tumour suppressor network. Nature 447: 1130-1134, 2007.

13. Tarasov V, Jung P, Verdoodt B, et al: Differential regulation of microRNAs by $\mathrm{p} 53$ revealed by massively parallel sequencing: miR-34a is a p53 target that induces apoptosis and G1-arrest. Cell Cycle 6: 1586-1593, 2007.

14. Chang TC, Wentzel EA, Kent OA, et al: Transactivation of miR-34a by 53 broadly influences gene expression and promotes apoptosis. Mol Cell 26: 745-752, 2007.
15. Welch C, Chen Y and Stallings RL: MicroRNA-34a functions as a potential tumor suppressor by inducing apoptosis in neuroblastoma cells. Oncogene 26: 5017-5022, 2007.

16. Bommer GT, Gerin I, Feng Y, et al: p53-mediated activation of miRNA34 candidate tumor-suppressor genes. Curr Biol 17: 1298-1307, 2007.

17. Toyota M,Suzuki H, Sasaki Y,Maruyama R,Imai K, Shinomura Y and Tokino T: Epigenetic silencing of microRNA-34b/c and B-cell translocation gene 4 is associated with $\mathrm{CpG}$ island methylation in colorectal cancer. Cancer Res 68: 4123-4132, 2008.

18. Kozaki K, Imoto I, Mogi S, Omura K and Inazawa J: Exploration of tumor-suppressive microRNAs silenced by DNA hypermethylation in oral cancer. Cancer Res 68: 2094-2105, 2008.

19. Lujambio A, Calin GA, Villanueva A, et al: A microRNA DNA methylation signature for human cancer metastasis. Proc Natl Acad Sci USA 105: 13556-13561, 2008.

20. Kong YW, Ferland-McCollough D, Jackson TJ and Bushell M: microRNAs in cancer management. Lancet Ooncol 13: e249-e258, 2012.

21. Lujambio A, Ropero S, Ballestar E, et al: Genetic unmasking of an epigenetically silenced microRNA in human cancer cells. Cancer Res 67: 1424-1429, 2007.

22. Iwai $\mathrm{N}$ and Naraba $\mathrm{H}$ : Polymorphisms in human pre-miRNAs. Biochem Biophys Res Commun 331: 1439-1444, 2005.

23. Xu Y, Liu L, Liu J, et al: A potentially functional polymorphism in the promoter region of miR-34b/c is associated with an increased risk for primary hepatocellular carcinoma. Int $\mathrm{J}$ Cancer 128: 412-417, 2011.

24. Gao LB, Li LJ, Pan XM, Li ZH, Liang WB, Bai P, Zhu YH and Zhang L: A genetic variant in the promoter region of $\mathrm{miR}-34 \mathrm{~b} / \mathrm{c}$ is associated with a reduced risk of colorectal cancer. Biol Chem 394: 415-420, 2013.

25. Hiroki E, Suzuki F, Akahira J, Nagase S, Ito K, Sugawara J, Miki Y, Suzuki T, Sasano H and Yaegashi N: MicroRNA-34b functions as a potential tumor suppressor in endometrial serous adenocarcinoma. Int J Cancer 131: E395-E404, 2012.

26. Bensen JT, Tse CK, Nyante SJ, Barnholtz-Sloan JS, Cole SR and Millikan RC: Association of germline microRNA SNPs in pre-miRNA flanking region and breast cancer risk and survival: the Carolina Breast Cancer Study. Cancer Causes Control 24: 1099-1109, 2013.

27. Ahmed RL, Schmitz KH, Anderson KE, Rosamond WD and Folsom AR: The metabolic syndrome and risk of incident colorectal cancer. Cancer 107: 28-36, 2006.

28. Moghaddam AA, Woodward M and Huxley R: Obesity and risk of colorectal cancer: a meta-analysis of 31 studies with 70,000 events. Cancer Epidemiol Biomarkers Prev 16: 2533-2547, 2007.

29. Wittke-Thompson JK, Pluzhnikov A and Cox NJ: Rational inferences about departures from Hardy-Weinberg equilibrium. Am J Hum Genet 76: 967-986, 2005.

30. Chou J, Provot S and Werb Z: GATA3 in development and cancer differentiation: cells GATA have it! J Cell Physiol 222: 42-49, 2010.

31. Xiang Y, Fan S, Cao J, Huang S and Zhang LP: Association of the microRNA-499 variants with susceptibility to hepatocellular carcinoma in a Chinese population. Mol Biol Rep 39: 7019-7023, 2012.

32. Lin J, Horikawa Y, Tamboli P, Clague J, Wood CG and Wu X: Genetic variations in microRNA-related genes are associated with survival and recurrence in patients with renal cell carcinoma. Carcinogenesis 31: 1805-1812, 2010.

33. Hu Z, Chen J, Tian T, et al: Genetic variants of miRNA sequences and non-small cell lung cancer survival. J Clin Invest 118: 2600-2608, 2008

34. Dumont P, Leu JI, Della Pietra AC III, George DL and Murphy M: The codon 72 polymorphic variants of p53 have markedly different apoptotic potential. Nat Genet 33: 357-365, 2003.

35. Irarrázabal CE, Rojas C, Aracena R, Márquez C and Gil L: Chilean pilot study on the risk of lung cancer associated with codon 72 polymorphism in the gene of protein p53. Toxicol Lett 144: 69-76, 2003.

36. Kuroda Y, Tsukino H, Nakao H, Imai H and Katoh T: $p 53$ codon 72 polymorphism and urothelial cancer risk. Cancer Lett 189: 77-83, 2003.

37. Suzuki K, Matsui H, Ohtake N, et al: A p53 codon 72 polymorphism associated with prostate cancer development and progression in Japanese. J Biomed Sci 10: 430-435, 2003.

38. Dahabreh IJ, Linardou H, Bouzika P, Varvarigou V and Murray S: TP53 Arg72Pro polymorphism and colorectal cancer risk: a systematic review and meta-analysis. Cancer Epidemiol Biomarkers Prev 19: 1840-1847, 2010. 